\title{
Expression of endothelia and lymphocyte adhesion molecules in bronchus-associated lymphoid tissue (BALT) in adult human lung Nakaaki Kawamata ${ }^{\dagger 1,2}$, Baohui Xu* ${ }^{*} 3,4$, Hiroo Nishijima ${ }^{5}$, Kohji Aoyama ${ }^{3}$, Mayumi Kusumoto ${ }^{3}$, Toru Takeuchi ${ }^{3}$, Chuwa Tei $^{2}$, Sara A Michie ${ }^{\dagger 4}$ and Takami Matsuyama ${ }^{\dagger 1}$
}

Address: ${ }^{1}$ Departments of Immunology, Graduate School of Medical and Dental Sciences, Kagoshima University, 8-35-1 Sakuragaoka, Kagoshima 890-8520, Japan, ${ }^{2}$ Cardiovascular, Respiratory and Metabolic Medicine, Graduate School of Medical and Dental Sciences, Kagoshima University, 8-35-1 Sakuragaoka, Kagoshima 890-8520, Japan, ${ }^{3}$ Environmental Medicine, Graduate School of Medical and Dental Sciences, Kagoshima University, 8-35-1 Sakuragaoka, Kagoshima 890-8520, Japan, ${ }^{4}$ Department of Pathology, School of Medicine, Stanford University, Stanford, CA 94305, USA and ${ }^{5}$ Department of Surgery, Kagoshima Kouseiren Hospital, Kagoshima, Japan

Email: Nakaaki Kawamata - kawamata@po5.synapse.ne.jp; Baohui Xu* - xubaohui@gmail.com; Hiroo Nishijima - kou.hsp-dr@ks-ja.or.jp; Kohji Aoyama - aoyama@m.kufm.kagoshima-u.ac.jp; Mayumi Kusumoto - kusumoto.mayumi@gmail.com;

Toru Takeuchi - takeuchi@m.kufm.kagoshima-u.ac.jp; Chuwa Tei - tei@m.kagoshima-u.ac.jp; Sara A Michie - smichie@stanford.edu; Takami Matsuyama - matuyama@m.kufm.kagoshima-u.ac.jp

* Corresponding author †Equal contributors

Published: 22 October 2009

Respiratory Research 2009, 10:97 doi:10.1186/1465-9921-10-97
Received: 17 August 2009

Accepted: 22 October 2009

This article is available from: http://respiratory-research.com/content/I0/I/97

(c) 2009 Kawamata et al; licensee BioMed Central Ltd.

This is an Open Access article distributed under the terms of the Creative Commons Attribution License (http://creativecommons.org/licenses/by/2.0), which permits unrestricted use, distribution, and reproduction in any medium, provided the original work is properly cited.

\begin{abstract}
Background: Bronchus-associated lymphoid tissue (BALT) is the secondary lymphoid tissue in bronchial mucosa and is involved in the development of bronchopulmonary immune responses. Although migration of lymphocytes from blood vessels into secondary lymphoid tissues is critical for the development of appropriate adaptive immunity, the endothelia and lymphocyte adhesion molecules that recruit specific subsets of lymphocytes into human BALT are not known. The aim of this study was to determine which adhesion molecules are expressed on lymphocytes and high endothelial venules (HEVs) in human BALT.
\end{abstract}

Methods: We immunostained frozen sections of BALT from lobectomy specimens from 17 patients with lung carcinoma with a panel of monoclonal antibodies to endothelia and lymphocyte adhesion molecules.

Results: Sections of BALT showed B cell follicles surrounded by $T$ cells. Most BALT CD4 ${ }^{+} T$ cells had a CD45RO+ memory phenotype. Almost all BALT $B$ cells expressed $\alpha_{4}$ integrin and L-selectin. In contrast, $43 \%$ of BALT T cells expressed $\alpha_{4}$ integrin and $20 \%$ of BALT T cells expressed Lselectin. Almost all BALT lymphocytes expressed LFA-I. HEVs, which support the migration of lymphocytes from the bloodstream into secondary lymphoid tissues, were prominent in BALT. All HEVs expressed peripheral node addressin, most HEVs expressed vascular cell adhesion molecule$\mathrm{I}$, and no HEVs expressed mucosal addressin cell adhesion molecule-I.

Conclusion: Human BALT expresses endothelia and lymphocyte adhesion molecules that may be important in recruiting naive and memory/effector lymphocytes to BALT during protective and pathologic bronchopulmonary immune responses. 


\section{Background}

The lower respiratory tract is continually exposed to a wide variety of airborne antigens and microorganisms. The generation of rapid, specific adaptive immune responses to inhaled antigens and pathogens is critical for survival. Unfortunately, in some inflammatory and infectious diseases, such as asthma and tuberculosis, these immune responses can damage the lungs and bronchi. Thus, the bronchopulmonary adaptive immune system is involved in the maintenance of health and the development of diseases of the lower respiratory tract.

In the initiation stage of an adaptive immune response, naive T cells migrate through blood vessel high endothelia venules (HEVs) into secondary lymphoid tissues, where they are stimulated by antigen-bearing dendritic cells. This leads to the generation of antigen-specific effector and memory $\mathrm{T}$ cells and B cells, which are released from the secondary lymphoid tissue into the bloodstream. In the effector stage of the adaptive immune response, some of the memory $\mathrm{T}$ cells and B cells migrate from blood vessels into nonlymphoid tissue(s) that contain the cognate antigens or pathogens [1-4]. The lower respiratory tract has two distinct types of secondary lymphoid tissues: bronchus-associated lymphoid tissue (BALT) and lymph nodes (LNs) [5-7]. The presence of BALT in adult mammals depends on species, antigen stimulation and age [68]. BALT is found in normal lungs of most healthy adult rabbits, rats, guinea pigs and old adult mice [5,6,9-13]. In contrast, the presence and frequency of BALT in normal lungs of healthy adult humans is controversial [5,14-20].

BALT is the site of initial presentation of inhaled antigens, which are transported from the bronchial lumen by specialized cells (likely $M$ cells and/or dendritic cells) in the epithelia over the BALT, to naive T cells, which enter the BALT through blood vessel HEVs [21-26]. Intravascular lymphocytes must bind to the endothelial surface of HEVs in BALT and other secondary lymphoid tissues, prior to migrating through the vessel wall into the tissue $[1,9,27]$. Thus, the adhesion molecules expressed on the surface of the HEVs help determine which subsets of lymphocytes can migrate into the tissue. There are three distinct, tissueselective combinations of adhesion molecules on HEVs in secondary lymphoid tissues. Most HEVs in peripheral LNs of mice and humans express peripheral node addressin (PNAd), but not mucosal addressin cell adhesion molecule-1 (MAdCAM-1) and vascular cell adhesion molecule1 (VCAM-1). Most HEVs in small intestine Peyer's patches (PP) express MAdCAM-1, but not VCAM-1 and luminal PNAd. Most HEVs in mouse BALT express PNAd and VCAM-1, but not MAdCAM-1 $[1,9,27]$. In vivo studies from our laboratory indicate that migration of B cells and naive $\mathrm{T}$ cells into mouse BALT largely depends on endothelial PNAd and its lymphocyte ligand L-selectin, while migration of memory $\mathrm{T}$ cells into BALT requires endothelial VCAM-1 and lymphocyte $\alpha_{4}$ integrin [9]. However, the adhesion molecules that are highly expressed on HEVs in human BALT are not known.

In this study, we evaluated BALT tissue from lobectomy specimens of 17 human adults with lung carcinoma. We found that BALT HEVs expressed PNAd and VCAM-1 but not MAdCAM-1. Most BALT B cells and some $\mathrm{T}$ cells expressed L-selectin and $\alpha_{4}$ integrin. Most BALT CD $4^{+} \mathrm{T}$ cells had a memory phenotype. These results suggest that human BALT expresses endothelia and lymphocyte adhesion molecules that may be important in recruiting naive and memory/effector lymphocytes to BALT, where they may be involved in the initiation of bronchopulmonary immune responses to inhaled antigens and pathogens.

\section{Methods \\ Tissue collection, frozen sectioning and histologic identification of BALT}

Bronchus tissue was obtained from 49 patients who underwent lobectomy for lung carcinoma at Kagoshima Kouseiren Hospital, Kagoshima, Japan. Patients with pulmonary inflammatory disorders, such as asthma, chronic obstructive pulmonary disease, rheumatoid lung, and post-obstructive pneumonia due to tumor, were excluded from the study. Tissue samples, each $\geq 2 \mathrm{~cm}$ in maximum dimension, of bronchus and surrounding lung were taken from at least 2 nonadjacent sites in each lobectomy specimen. The sampling was carefully performed to exclude tumor. Each tissue sample was infused with a 1:1 mixture of OCT compound (Sakura Finetek, Tokyo, Japan) and phosphate-buffered saline (PBS), and frozen in OCT compound. A frozen section was cut, fixed in methanol, stained with hematoxylin and examined by light microscopy for "classic" BALT, as defined using the histologic criteria originally described and illustrated by Bienenstock and colleagues [5]. These criteria are listed in the first paragraph of the Results section. If "classic" BALT was identified on the hematoxylin-stained section, additional sections were cut, fixed in acetone, and stored at $-20^{\circ} \mathrm{C}$ for immunostaining. If there was no BALT on the hematoxylin-stained section, we continued to cut and examine sections at $100 \mu \mathrm{m}$ intervals until BALT was found, or the block was cut through.

Small intestine PPs, obtained from ileocecal resection specimens from 3 patients with colon carcinoma, were frozen in OCT compound. Frozen sections were cut, fixed in acetone, and stored at $-20^{\circ} \mathrm{C}$ for immunostaining.

\section{Antibodies and other reagents}

Mouse and rat monoclonal antibodies (mAbs) used in this study are listed in Table 1. Biotin-anti-mouse IgG polyclonal antibody was purchased from eBioscience (San 
Table I: Monoclonal Antibodies Used for Tissue Immunostaining

\begin{tabular}{|c|c|c|c|}
\hline mAb & Clone & Species Isotype & Source \\
\hline CD3 & UCHTI & mouse IgGI & BD Biosciences \\
\hline CD4 & RPA-T4 & mouse IgGI & eBioscience \\
\hline CD8 & RPA-T8 & mouse IgGI & eBioscience \\
\hline CDI9 & HIBI9 & mouse $\lg G \mid$ & BD Biosciences \\
\hline CD45RA & HIIOO & mouse lgG2b & BD Biosciences \\
\hline CD45RO & UCHLI & mouse lgG2a & eBioscience \\
\hline CDIIa/LFA-I & HIIII & mouse IgGI & eBioscience \\
\hline CD49d/ $\alpha_{4}$ integrin & $9 F I 0$ & mouse lgGI & eBioscience \\
\hline CD62L/L-selectin & Dreg 56 & mouse IgGI & BD Biosciences \\
\hline CD3I/PECAM-I & WM59 & mouse IgGI & eBioscience \\
\hline CD54/ICAM-I & HA58 & mouse IgGI & eBioscience \\
\hline CDI02/ICAM-2 & CBR/IC2/2 & mouse $\lg G 2 a$ & Caltag Laboratories \\
\hline MAdCAM-I & MMC3 & mouse IgGI & Dina Washington, Genentech \\
\hline PNAd & MECA79 & rat $\lg M$ & Dr. Eugene C. Butcher, Stanford University \\
\hline CDI06/VCAM-I & D8 & mouse $\lg G \mid$ & Dr. Takami Matsuyama, Kagoshima University \\
\hline \multirow[t]{4}{*}{ Species and isotype matched negative controls } & $N / A$ & mouse IgGI & eBioscience \\
\hline & $N / A$ & mouse $\lg G 2 a$ & eBioscience \\
\hline & N/A & mouse IgG2b & eBioscience \\
\hline & OZ42 & rat $\lg M$ & Dr. Leslie Pickford \\
\hline
\end{tabular}

Diego, CA). Biotin-anti-rat IgM polyclonal antibody and peroxidase-streptavidin were obtained from Jackson ImmunoResearch Laboratories (West Grove, PA). AEC substrate kit and Alexa Fluor 546-streptavidin were from Vector Laboratories (Burlingame, CA) and Molecular Probes (Eugene, OR), respectively.

\section{Immunohistochemical staining}

Acetone-fixed frozen sections of BALT and PP were incubated with mAb against CD31, MAdCAM-1, VCAM-1 or PNAd, or with a species- and isotype-matched negative control mAb, at room temperature for 1 hour (hr). Sections were rinsed in PBS, incubated with biotin-antimouse IgG (to detect CD31, MAdCAM-1 or VCAM-1) or biotin-anti-rat IgM (to detect PNAd) at room temperature for 30 minutes (min), rinsed in PBS, and incubated with peroxidase-streptavidin for $30 \mathrm{~min}$. After a final PBS wash, slides were incubated with Vector AEC substrate (per manufacturer's instructions), stained with hematoxylin, and cover-slipped. Sections were evaluated by light microscopy.

\section{Immunofluorescence (IF) staining}

To evaluate expression of ICAM-1 and ICAM-2 on blood vessel endothelia, frozen sections of BALT and PP were sequentially incubated with anti-ICAM- $1 \mathrm{mAb}$, antiICAM-2 mAb or negative control mAb (1 hr), biotin-antimouse IgG (30 min), and Alexa Fluor 546-streptavidin (30 min).
To identify B cells and T cells, frozen sections of BALT and PP were sequentially incubated with anti-CD19 mAb (1 $\mathrm{hr}$ ), biotin-anti-mouse IgG (30 $\mathrm{min}), 10 \%$ normal mouse serum (30 min), and Alexa Fluor 546-streptavidin combined with FITC-anti-CD3 mAb (30 min). CD4+ cells and $\mathrm{CD} 8+$ cells were identified by incubating the sections with PE-anti-CD4 and FITC-anti-CD8 mAbs (30 min). Naive $\mathrm{CD} 4{ }^{+}$cells were identified by staining with PE-anti-CD4 and FITC-anti-CD45RA mAbs, while memory CD4+ cells were identified by staining with PE-anti-CD4 and FITCanti-CD45RO mAbs. We counted $\mathrm{CD} 4{ }^{+} \mathrm{CD} 45 \mathrm{RA}^{+}$cells (naive $\mathrm{CD} 4^{+} \mathrm{T}$ cells) and $\mathrm{CD} 4{ }^{+} \mathrm{CD} 45 \mathrm{RO}^{+}$cells (memory CD4 ${ }^{+} \mathrm{T}$ cells) in BALT from 7 randomly selected patients, and calculated the percent of $\mathrm{CD} 4{ }^{+} \mathrm{T}$ cells with naive or memory phenotype.

To evaluate co-expression of VCAM-1 and PNAd on BALT HEVs, sections were sequentially incubated with antiVCAM-1 mAb (1 hr), biotin-anti-mouse IgG in $4 \%$ normal human serum (30 min), 10\% normal rat serum (30 min), and FITC-anti-PNAd mAb combined with Alexa Fluor 546-streptavidin (30 min). In 5 randomly selected patients, we determined the percentage of PNAd ${ }^{+} \mathrm{HEVs}$ that expressed VCAM-1.

To evaluate expression of adhesion molecules on BALT lymphocytes, sections were incubated with FITC-antiCD3 mAb combined with PE-anti-LFA-1, PE-anti- $\alpha_{4}$ integrin, or PE-anti-L-selectin mAb (30 min). We counted 
total $\mathrm{T}$ cells $\left(\mathrm{CD}^{+}\right)$and $\mathrm{T}$ cells expressing LFA-1, $\alpha_{4}$ integrin or L-selectin in BALT from 6 randomly selected patients, and calculated the percentage of $\mathrm{T}$ cells that expressed each adhesion molecule. In a similar manner, we determined the proportion of $\mathrm{B}$ cells (CD3- lymphocytes in the B cell follicle) that expressed each adhesion molecule.

For each tissue, primary mAbs were replaced by conjugation-, species- and isotype-matched negative control mAbs. All slides were viewed and imaged using a confocal microscope.

\section{Ethics}

The ethics committee of the Graduate School of Medical and Dental Sciences, Kagoshima University, Japan approved this study. Each patient gave written informed consent to use tissue for research.

\section{Statistical analysis}

All data are expressed as mean \pm standard derivation (SD). Chi-square test was used to evaluate the difference in the frequency of BALT between groups. $P<0.05$ was considered to be statistically significant.

\section{Results \\ Detection of BALT in adult human lung}

We examined hematoxylin-stained frozen sections of bronchi from lung carcinoma lobectomy specimens for BALT. We used histologic criteria that were originally proposed by Bienenstock and are extensively described in the human histopathology literature $[5,28,29]$. Specifically, BALT: 1) consists of lymphoid follicle(s) in the bronchial mucosa; 2) is fairly well circumscribed, without inflammation or damage of the adjacent bronchus tissue, 3) has prominent HEVs, and no or small germinal centers; 4) may contain pigment-filled macrophages, but no neutrophils or eosinophils; and 5) lacks evidence of significant epithelial injury. If BALT was identified on the hematoxylin-stained section (Fig. 1A), we immediately cut additional sections from the frozen tissue block for immunohistology staining. In some specimens, we found a few small, poorly demarcated lymphoid aggregates in the pulmonary parenchyma (Fig. 1B). These aggregates, which were not associated with a bronchus, were not analyzed in this study.

We identified BALT on hematoxylin-stained frozen sections of bronchus from 17/49 (35\%) lung lobectomy specimens (Fig. 1A). BALT was identified in $40 \%$ of the lobectomy specimens from men and $26 \%$ of the specimens from women. Current smokers (42\%) were more likely to have BALT than were previous smokers $(25 \%)$ or non-smokers $(29 \%)$. BALT was slightly more common in patients over the age of 70 years $(37 \%)$ than in those 70

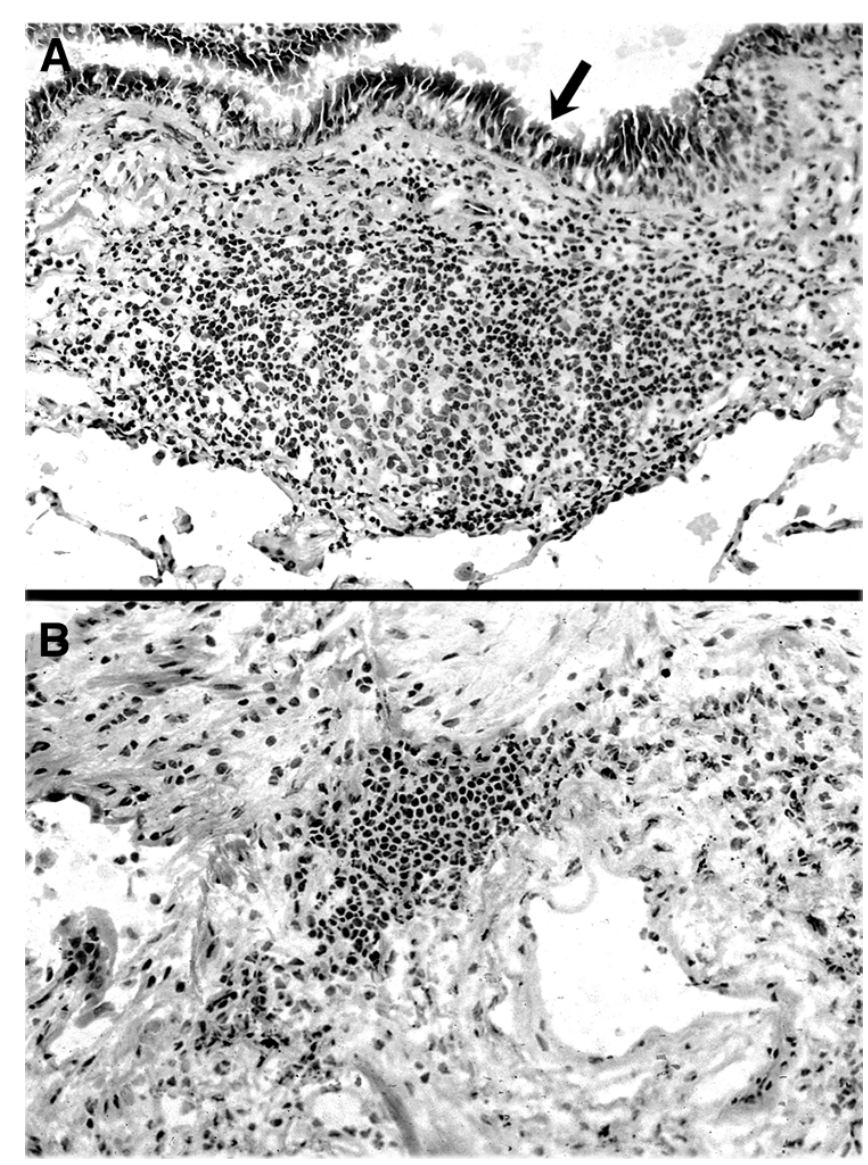

Figure 1

Lymphoid tissue in human lung. (A): Bronchus-associated lymphoid tissue (BALT). There is a well demarcated submucosal lymphoid follicle in the wall of a bronchus. The arrow is in the bronchial lumen, pointing to the bronchial epithelia. (B): Nonspecific lymphoid aggregate. There is a small, poorly demarcated lymphoid aggregate in a small focus $(<1 \mathrm{~mm}$ diameter) of scar tissue in the lung interstitium. The aggregate is not associated with a bronchus. This aggregate does not meet the histologic criteria for BALT and is not included in this study. (hematoxylin and eosin stained frozen sections; original magnification 200x).

years or younger (32\%). BALT was found in $43 \%$ of patients with squamous cell carcinoma and $31 \%$ of patients with adenocarcinomas. None of these differences were statistically significant ( $p>0.05$ for all factors, Chisquare test).

\section{Adhesion molecules on BALT HEVs}

To determine which adhesion molecules are expressed on BALT HEVs, we stained frozen sections of BALT with mAbs against endothelia adhesion molecules that are expressed by HEVs in secondary lymphoid tissues. These adhesion molecules include PNAd, which is highly expressed by HEVs in peripheral LNs and mouse BALT; 
MAdCAM-1, which is expressed by HEVs in small intestine PPs; VCAM-1, which is highly expressed by HEV endothelia in mouse BALT; and ICAM-1 and ICAM-2, which are expressed by HEVs in LNs, PPs and mouse BALT $[1,9]$. For comparison to BALT, we also stained sections of PP.

There was strong expression of PNAd on all HEVs in BALT (Fig. 2A) and on a few small vessels in PP (Fig. 2B). VCAM-1 was expressed on many HEVs in BALT, on rare HEVs in PP, and on many non-endothelial cells in BALT and PP (Figs. 2C, D). There was no staining for MAdCAM1 on BALT HEVs in any of the patients (Fig. 2E). Bronchial venules that were not in BALT did not express PNAd, VCAM-1 or MAdCAM-1 (not shown), indicating that the bronchi were not chronically inflamed. As expected, there was strong staining for MAdCAM-1 on PP HEVs (Fig. 2F) [30]. ICAM-1 and ICAM-2 were strongly expressed on HEVs in BALT and PP (data not shown). Negative control mAbs did not stain vascular endothelia in BALT or PP sections (Figs. 2G, H).

VCAM-1 is known to be expressed by a variety of nonendothelial cells, including follicular dendritic cells and blood vessel pericytes, in human secondary lymphoid tissues [31]. Because of this extensive expression, it is difficult to determine which cells are stained with an antiVCAM-1 mAb on single color immunohistology slides (Figs. 2C, D). To focus on VCAM-1 expression by HEV endothelia, we stained frozen sections of BALT for PNAd and VCAM-1 by two-color IF (Figs. 2I-N). Quantitative evaluation revealed that $66 \pm 11 \%$ of BALT HEVs, as identified by high endothelial morphology and expression of PNAd, were PNAd ${ }^{+}$VCAM- ${ }^{+}$and $33 \pm 11 \%$ were PNAd+VCAM-1- $(n=5$ patients $)$.

These results indicate that the HEV adhesion molecules that are available to recruit lymphocytes into BALT differ significantly from those that are available to recruit lymphocytes into PP. Specifically, in BALT, all HEVs expressed PNAd, most HEVs expressed VCAM-1, and no HEVs expressed MAdCAM-1. In PP, all HEVs expressed MAdCAM-1 and a few small HEVs expressed PNAd or VCAM-1.

\section{Lymphocytes in BALT}

We used two-color frozen section IF staining to determine which lymphocyte subsets are present in BALT, and whether certain subsets occupy specific microenvironments within the tissue. Our stains revealed well demarcated $\mathrm{B}\left(\mathrm{CD} 19^{+}\right)$and $\mathrm{T}\left(\mathrm{CD}^{+}\right)$cell zones (Fig. 3A). The B cells formed central aggregates that were surrounded by $\mathrm{T}$ cells, most of which expressed CD4 (Figs. 3A and 3B). CD45RO (memory marker) and CD45RA (naive marker) were expressed on $86 \pm 2 \%$ and $9 \pm 2 \%$ of the CD $4+$ T cells ( $n=7$ patients), respectively (Figs. $3 \mathrm{C}$ and $3 \mathrm{D})$.
Next, we examined BALT T cells and B cells for the expression of L-selectin, which binds to PNAd; $\alpha_{4}$ integrin, which is a subunit of $\alpha_{4} \beta_{1}$ integrin (which binds mainly to VCAM-1) and $\alpha_{4} \beta_{7}$ integrin (which binds to MAdCAM-1); and LFA-1, which binds to ICAM-1 and ICAM-2 [1]. Most T cells (96 $\pm 5, n=6$ patients) expressed LFA-1 (Fig. 3E). A minority of T cells expressed $\alpha_{4}$ integrin $(43 \pm 12 \%)$ or Lselectin $(20 \pm 19 \%)$ (Figs. $3 \mathrm{~F}$ and $3 \mathrm{G})$. In contrast, almost all B cells expressed LFA-1, $\alpha_{4}$ integrin and L-selectin. BALT lymphocytes did not stain with the negative control mAbs (Fig. 3H). Thus, BALT T cells differ from BALT B cells in expression of adhesion molecules that are involved in lymphocyte migration from the bloodstream into tissues.

\section{Discussion}

Migration of lymphocytes from blood vessels into tissues is a complex process with multiple adhesion and activation steps [1,32]. Briefly, lymphocytes transiently adhere to the endothelial surface of venules in the tissue (step 1), are activated by chemokines (step 2), and adhere firmly to the endothelia (step 3), before migrating through the vessel wall into the tissue $[1,32]$. Thus, the adhesion molecules that are expressed on the HEVs in a secondary lymphoid tissue are important in determining which subsets of lymphocytes migrate into the tissue. Here we evaluated BALT from lobectomy specimens of 17 human adults with lung carcinoma for the expression of HEV and lymphocyte adhesion molecules that might recruit lymphocytes from blood vessels into BALT. We found that BALT HEV expressed PNAd, ICAM-1 and ICAM-2, with or without VCAM-1. MAdCAM-1 was not expressed on HEVs in any of the BALT samples. The adhesion molecule profile of HEVs in human BALT is similar to that of HEVs in mouse BALT, differing only in the extent of VCAM-1 expression (66\% of HEVs in human and $91 \%$ of HEVs in mouse BALT) [9]. Thus, BALT in humans, as in mice [9], has HEV adhesion molecules that are capable of recruiting distinct subsets of lymphocytes from the bloodstream into the tissue.

As in mice, the combination of adhesion molecules on HEVs in human BALT differs from that on HEVs in other secondary lymphoid tissues [9]. Specifically, VCAM-1, which was expressed by endothelia of $66 \%$ of BALT HEVs in our study, is not significantly expressed on HEV endothelia in PP (Fig. 2D), adenoids and peripheral LNs $[31,33]$. PNAd, which was strongly expressed on all HEVs in BALT, is weakly expressed on HEVs in appendix and PP (Fig. 2B) [34]. MAdCAM-1, which was not expressed on BALT HEVs, is strongly expressed on appendix and PP HEVs [30].

We found that $86 \%$ of BALT CD $4+$ T cells had a memory phenotype $\left(\mathrm{CD} 4^{+} \mathrm{CD} 45 \mathrm{RO}^{+}\right)$. Since BALT does not have afferent lymphatic vessels [6], these memory T cells may 


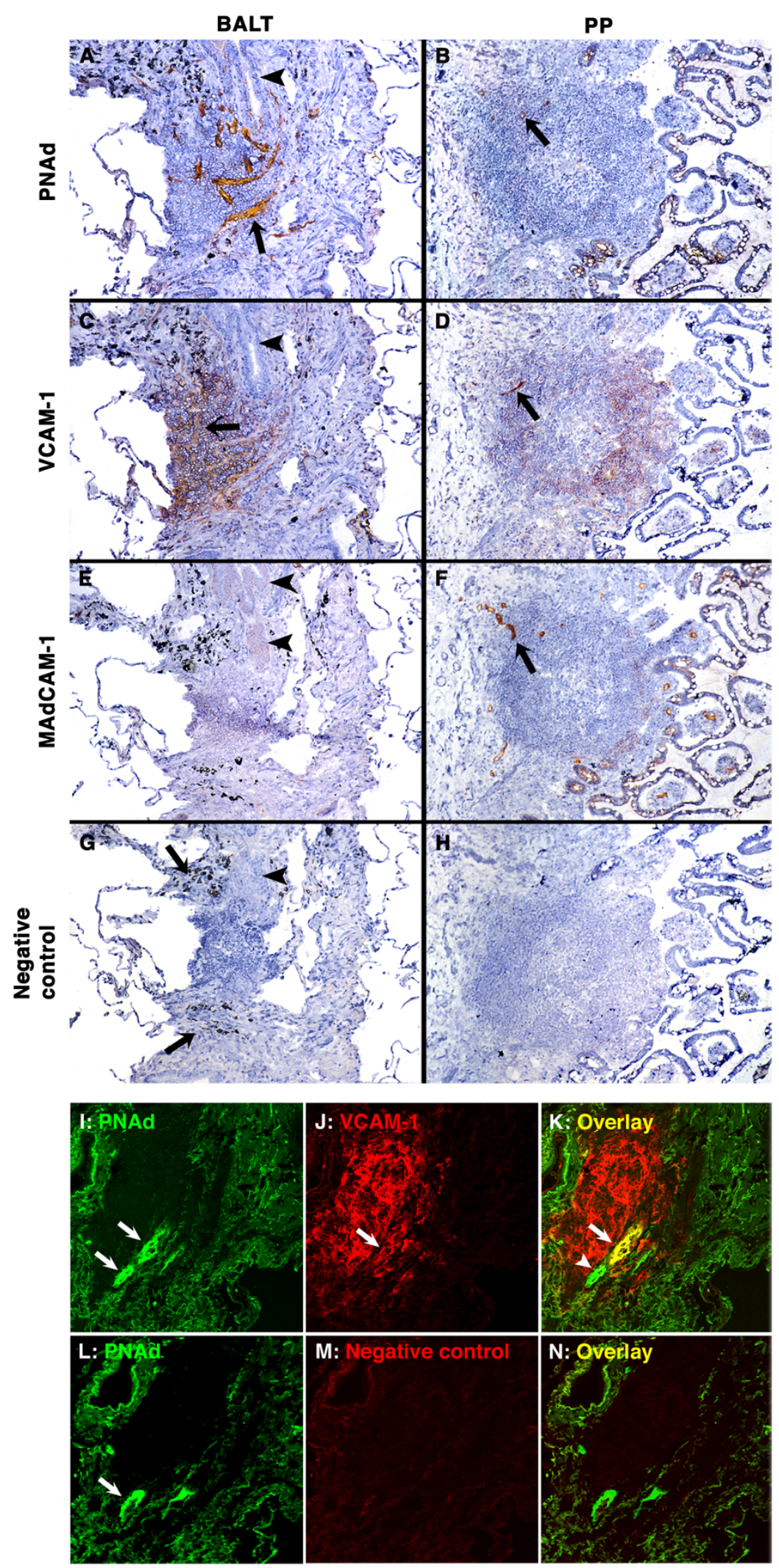

Figure 2 (see legend on next page) 
Figure 2 (see previous page)

PNAd and VCAM-I are expressed on HEVs in human BALT. (A-H): Semi-serial frozen sections of BALT (A, C, E, G; arrowheads highlight the bronchial epithelium) and $P P(B, D, F, H)$ were stained with mAbs against PNAd (A, B), VCAM-I (C, $D)$ and MAdCAM-I (E, F), or with an isotype-matched negative control mAb $(G, H)$. (A and B) PNAd is expressed on BALT HEVs (A; arrow highlights one HEV) and on a few vessels in PP (B; arrow). (C and D) VCAM-I is expressed on BALT HEVs (C; arrow highlights one HEV) and on one vessel in PP (D; arrow). VCAM-I is also expressed on non-endothelial cells in BALT and PP. (E and F) MAdCAM-I is expressed on vessels in PP (F; arrow), but not in BALT (E). ( $G$ and $H$ ) Mouse IgGI (for antiVCAM-I and MAdCAM-I) and rat IgM (for anti-PNAd mAb; not shown) negative control mAbs did not stain HEVs in BALT $(G)$ and PP $(H)$. (A, C, E, G) The black granular material (highlighted by arrows in $G$ ) is carbon pigment in macrophages. (immunoperoxidase stains. original magnification I00x). (I-N): Semi-serial frozen sections of BALT were stained with $\mathrm{mAbs}$ against PNAd (green) and VCAM-I (red) (I-K) or with anti-PNAd mAb (green) and negative control mAb (L-N) by two-color immunofluorescence. Anti-PNAd mAb gave strong staining of BALT HEVs (I, L; arrows). The anti-VCAM-I mAb stained HEVs (J; arrow) and non-endothelial cells in BALT. PNAd ${ }^{+}$VCAM- I+ $(K$; arrow) and PNAd + VCAM- - (K; arrowhead) HEVs were found in BALT. The negative control mAb for VCAM-I did not stain BALT (M, N). (two-color immunofluorescence stains. original magnification 200x).

have migrated through blood vessel HEVs into BALT and/ or may have arisen in situ from the maturation of naive T cells. As in other secondary lymphoid tissues, BALT T cells differ from B cells in adhesion molecule expression. Lselectin, which binds to PNAd, was expressed on $20 \%$ of T cells and almost all B cells in BALT. $\alpha_{4}$ integrin, which is a subunit of $\alpha_{4} \beta_{1}$ integrin that binds to VCAM-1, was expressed on $43 \%$ of T cells and almost all B cells in BALT. LFA-1, which binds to ICAM-1 and ICAM-2, was expressed on almost all lymphocytes in BALT.

The Stamper-Woodruff in vitro binding assay can be used to determine which adhesion molecules mediate the binding of viable lymphocytes to HEVs on frozen sections of tissues [12,35]. Due to the scarcity of frozen samples of human BALT, we were unable to perform these assays. However, our immunohistology studies on human and mouse BALT and our functional studies on mouse BALT [9] suggest that PNAd and VCAM-1 are involved in organselective recruitment of specific subsets of lymphocytes to human BALT. Specifically, L-selectin ${ }^{+}$naive T cells could be recruited from the bloodstream into human BALT by binding to PNAd ${ }^{+}$HEVs [36]. Since specialized cells, such as $M$ cells and/or dendritic cells, transport airway luminal antigens into BALT, the naive T cells could meet antigenbearing dendritic cells in BALT, resulting in the generation of lung-specific $\alpha_{4} \beta_{1}$ integrin $^{+}$memory T cells. Following release into the bloodstream, the $\alpha_{4} \beta_{1}$ integrin $^{+}$memory $\mathrm{T}$ cells could be recruited back to BALT by binding to VCAM-1+ HEVs. Additionally, the $\alpha_{4} \beta_{1}$ integrin ${ }^{+}$memory $\mathrm{T}$ cells could migrate into inflamed lungs by binding to VCAM-1, which is highly expressed on vessels in human inflamed lung [37-39]. Thus, in humans as in mice, the VCAM- $1 / \alpha_{4} \beta_{1}$ integrin adhesion system may unify the migration pathways of $\mathrm{T}$ cells into BALT and inflamed lung.
The frequency of BALT in normal lungs of healthy adults varies considerably between species. For example, BALT is found in lungs of most normal adult rats, rabbits and guinea pigs $[5,6,10,12,13,40]$. In contrast, the existence of BALT in lungs of healthy adult humans is controversial. In published reports, BALT was found in $0 \%$ to $74 \%$ of normal human lungs, as compared to $35 \%$ of lungs in our study $[14-16,18,20,41]$. The marked differences in the frequency of human BALT between studies may be due to several factors, including the criteria used to determine if the lung is "normal" and/or the person is "healthy", differences in human subject populations, the source and size of the specimen (i.e., bronchial biopsy, surgical wedge resection, or surgical resection of a lobe or lung), the number of tissue samples and sections examined, and the histologic criteria used to identify BALT.

As with other lymphoid tissues, BALT can undergo marked changes in size, cellular composition, and function during local immune responses. In animal models, BALT can be induced and/or activated by infection or immune stimulation of the lower respiratory tract $[23,42$ 45]. In humans, hyperplastic BALT can be seen in patents with chronic pulmonary inflammatory disorders, such as hypersensitivity pneumonitis, and in patients with autoimmune diseases, including rheumatoid arthritis and Sjogren's syndrome $[15,46-50]$. Exposure to irritants, such as those in cigarette smoke, may influence the development of BALT, as BALT was found in $82 \%$ of smoking and $14 \%$ of non-smoking human adults in one study [18]. In our study, BALT was slightly more common in current smokers (42\%) than in non-smokers (29\%).

It is clear from this study and previous studies that human BALT shares many features with secondary lymphoid tissues, including distinct $\mathrm{T}$ cell and B cell zones, follicular dendritic cells, PNAd ${ }^{+} \mathrm{HEVs}$, and expression of lymphoid chemokines CXCL13 and CCL21 (Fig. 2) [49]. Some 

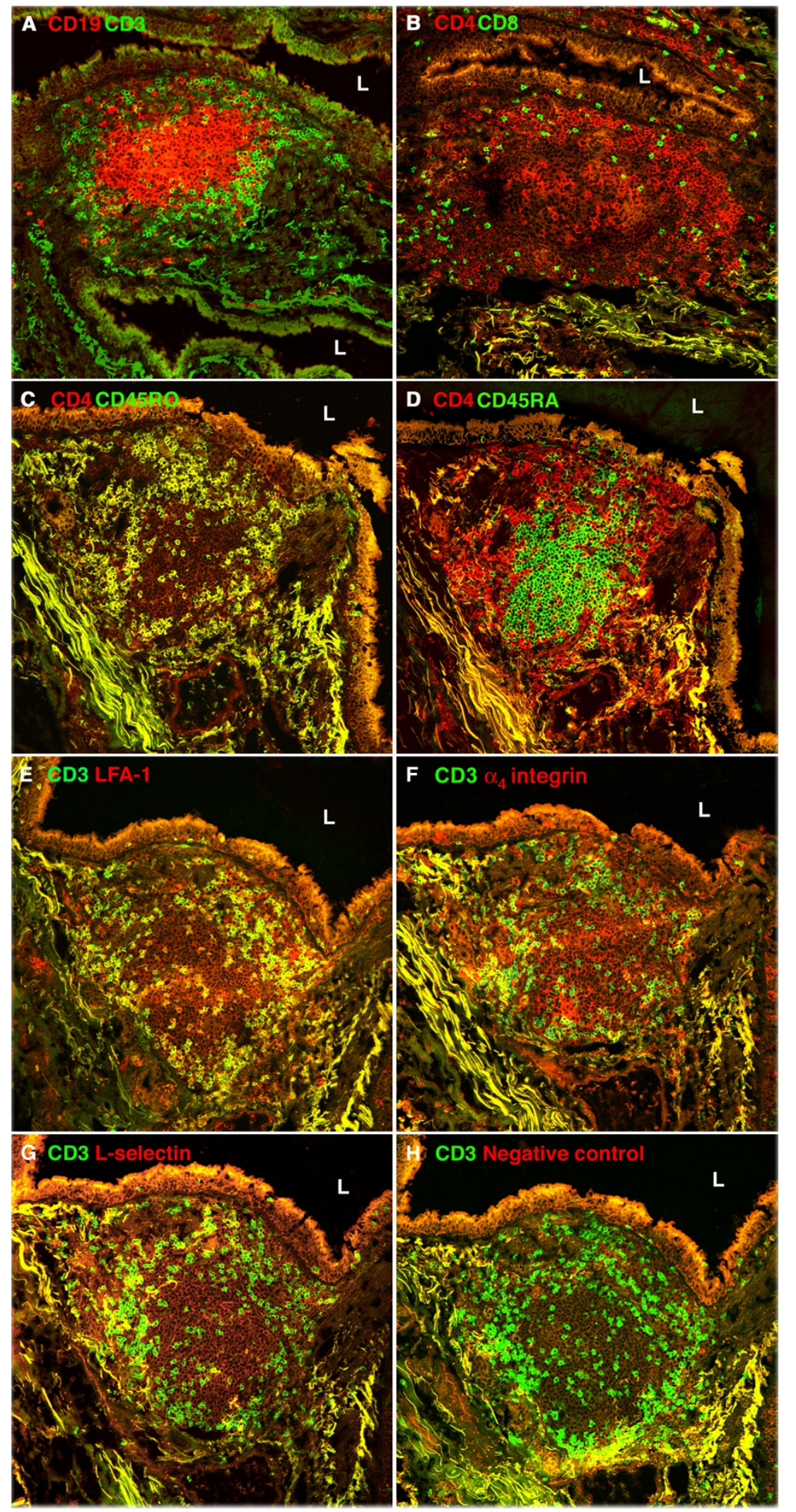

Figure 3 (see legend on next page) 
Figure 3 (see previous page) Lymphocytes in human BALT. (A-D): Semi-serial frozen sections of BALT were stained with mAbs against CDI9 and CD3 (A), CD4 and CD8 (B), CD4 and CD45RO (C), and CD4 and CD45RA (D). $L$ is in the airway lumen of the bronchus. (A) $B$ cell follicle (CDI9+, red) surrounded by T cells (CD3+, green). (B) CD4+ cells (red) outnumber CD8 ${ }^{+}$cells (green). (C) Almost all BALT CD4 ${ }^{+}$cells have a memory phenotype (CD4 ${ }^{+} \mathrm{CD} 45 \mathrm{RO}^{+}$; yellow). (D) $\mathrm{CD}^{+}$cells with a naive phenotype $\left(C D 4+C D 45 R^{+}\right.$, yellow) are very rare in BALT. Most cells in the B cell follicle are CD4-CD45RA ${ }^{+}$(green). (E-H): Semi-serial frozen sections of BALT from a different patient were stained with FITC-anti-CD3 mAb combined with a PE-conjugated mAb against an adhesion molecule or a negative control antigen. $L$ is in the airway lumen of the bronchus. Most BALT T cells, as defined by expression of CD3, also expressed LFA-I (E, yellow); a minority of BALT T cells expressed $\alpha_{4}$ integrin (F, yellow) or L-selectin (G, yellow). In contrast, most BALT B cells (CD3-) express LFA-I (E, red), $\alpha_{4}$ integrin (F, red) and L-selectin (G, red). The PE-negative control mAb did not stain T or B cells in BALT $(H)$. (two-color immunofluorescence stains. original magnification 200x).

unique features of BALT in humans and animals, however, lead to the debate regarding whether BALT is a secondary lymphoid tissue controlled by a precise developmental program or a tertiary lymphoid tissue controlled by lymphoid neogenesis. BALT varies by species, strain, age, and antigen stimulation: it is more common in rabbits and rats than in mice $[5,6,10,13,40]$; autoimmune-prone nonobese diabetic mice and old mice have more prominent BALT than nonautoimmune-prone and young mice, respectively [9]; and antigen stimulation and microbe infection can induce BALT formation in lungs of mice $[23,42,43,51]$. Additionally, HEVs in mouse and human BALT express VCAM-1 (Fig. 2) [9], which is frequently seen on HEVs of tertiary lymphoid tissues but not of LNs and PPs [52]. Thus, BALT is not identical to "conventional" secondary lymphoid tissues such as LNs and PPs.

A limitation of our study and of several other studies of human bronchopulmonary immunology [35,53] is that the tissues were obtained from carcinoma lobectomy specimens. The factors, such as cigarette smoke, that led to the development of the carcinoma could also lead to the development of chronic inflammation, such as chronic bronchitis. In addition, the carcinoma could initiate an inflammatory response (for example, by obstructing a bronchus, leading to post-obstructive pneumonia). We made every effort to minimize these potential confounding factors. Specifically, we excluded patients with 1) known inflammatory pulmonary diseases; 2) macroscopic evidence of inflammation or infection in the lobectomy specimen; or 3) histologic features of inflammation or infection [29]. Moreover, we used strict histopathologic criteria to identify "classic" BALT as described by Bienenstock and colleagues and in the pathology literature $[5,29]$.

\section{Conclusion}

In summary, we found that the HEVs in human BALT express a unique set of adhesion molecules that are very similar to those expressed in mouse BALT but markedly different from those expressed in other human secondary lymphoid tissues. The adhesion molecules on human BALT HEVs may be important in recruiting specific subsets of naive and memory/effector lymphocytes to BALT, where they may be involved in the development of bronchopulmonary immune responses to inhaled antigens and pathogens. Thus, BALT may be involved in the induction or/and modification of physiologic and pathologic bronchopulmonary immune responses. Selective targeting of PNAd/L-selectin- and VCAM- $1 / \alpha_{4} \beta_{1}$ integrin-mediated lymphocyte migration pathways might serve as a novel strategy for treating inflammatory bronchopulmonary diseases.

\section{List of abbreviations}

BALT: bronchus-associated lymphoid tissue; HEVs: high endothelial venules; Hr: hour; IF: immunofluorescence; LNs: lymph nodes; mAb: monoclonal antibody; MAdCAM-1: mucosal addressin cell adhesion molecule-1; Min: minutes; PBS: phosphate-buffered saline; PNAd: peripheral node addressin; PPs: Peyer's patches; SD: Standard derivation; VCAM-1: vascular cell adhesion molecule-1

\section{Competing interests}

The authors declare that they have no competing interests.

\section{Authors' contributions}

NK and BHX contributed equally as co-first authors. SAM and TM contributed equally as co-senior authors. NK, BHX, SAM and TM designed the project, analyzed and interpreted the data, and wrote the manuscript. HN performed the lobectomies, collected and processed specimens, obtained written informed consent from all patients, and participated in data interpretation. NK, BHX, KA and MK performed experiments. CT and TT participated in data analysis and interpretation. All authors read and approved the final manuscript.

\section{Acknowledgements}

We thank Dr. Eugene C. Butcher at Stanford University and Dina Washington at Genentech Inc for providing mAbs for this study. This work was sup- 
ported by grants from the Japan Society for Science Promotion to Takami Matsuyama (C2-I I670435) and Baohui Xu (C2-I267I664); a Digestive Disease Center grant (DK56339) from the NIH; and grants from the NIH (ROI DEOI4385) and Sjogren's Syndrome Foundation to Sara Michie.

\section{References}

I. Butcher EC, Picker LJ: Lymphocyte homing and homeostasis. Science 1996, 272:60-66.

2. Dutton RW, Bradley LM, Swain SL: T cell memory. Annu Rev Immunol 1998, 16:201-223.

3. Jenkins MK, Khoruts A, Ingulli E, Mueller DL, McSorley SJ, Reinhardt $R L$, Itano $A$, Pape KA: In vivo activation of antigen-specific CD4 T cells. Annu Rev Immunol 2001, I 9:23-45.

4. Sprent J, Surh CD: T cell memory. Annu Rev Immunol 2002, 20:55I-579.

5. Bienenstock J, Johnston N: A morphologic study of rabbit bronchial lymphoid aggregates and lymphoepithelium. Lab Invest 1976, 35:343-348.

6. Sminia T, Brugge-Gamelkoorn GJ van der, Jeurissen SH: Structure and function of bronchus-associated lymphoid tissue (BALT). Crit Rev Immunol 1989, 9: I 19-150.

7. Bienenstock J, McDermott MR: Bronchus- and nasal-associated Iymphoid tissues. Immunol Rev 2005, 206:22-3I.

8. Bienenstock J, Befus D: Gut- and bronchus-associated lymphoid tissue. Am J Anat 1984, I 70:437-445.

9. Xu B, Wagner N, Pham LN, Magno V, Shan Z, Butcher EC, Michie SA: Lymphocyte homing to bronchus-associated lymphoid tissue (BALT) is mediated by L-selectin/PNAd, alpha4betal integrin/VCAM-I, and LFA-I adhesion pathways. I Exp Med 2003, I97: 1255-1267.

10. Plesch BE, Gamelkoorn G], Ende M van de: Development of bronchus associated lymphoid tissue (BALT) in the rat, with special reference to $\mathbf{T}$ - and B-cells. Dev Comp Immunol 1983, 7:179-188.

II. Sato A: [Basic and clinical aspects of bronchus-associated lymphoid tissue]. Nihon Kokyuki Gakkai Zasshi 2000, 38:3-II.

12. Brugge-Gamelkoorn GJ van der, Kraal G: The specificity of the high endothelial venule in bronchus-associated lymphoid tissue (BALT). J Immunol 1985, I 34:3746-3750.

13. Simecka JW, Davis JK, Cassell GH: Distribution of la antigens and T lymphocyte subpopulations in rat lungs. Immunology 1986, 57:93-98.

14. Hiller AS, Tschernig T, Kleemann WJ, Pabst R: Bronchus-associated lymphoid tissue (BALT) and larynx-associated lymphoid tissue (LALT) are found at different frequencies in children, adolescents and adults. Scand J Immunol 1998, 47:159-162.

15. Tschernig T, Pabst R: Bronchus-associated lymphoid tissue (BALT) is not present in the normal adult lung but in different diseases. Pathobiology 2000, 68: $1-8$.

16. Tschernig T, Kleemann WJ, Pabst R: Bronchus-associated lymphoid tissue (BALT) in the lungs of children who had died from sudden infant death syndrome and other causes. Thorax 1995, 50:658-660.

17. Gould SJ, Isaacson PG: Bronchus-associated Iymphoid tissue (BALT) in human fetal and infant lung. J Pathol 1993, l 69:229-234.

18. Richmond I, Pritchard GE, Ashcroft T, Avery A, Corris PA, Walters $\mathrm{EH}$ : Bronchus associated lymphoid tissue (BALT) in human lung: its distribution in smokers and non-smokers. Thorax 1993, 48: I I30-I I34.

19. Sue-Chu M, Karjalainen EM, Altraja A, Laitinen A, Laitinen LA, Naess $A B$, Larsson $L$, Bjermer $L$ : Lymphoid aggregates in endobronchial biopsies from young elite cross-country skiers. $\mathrm{Am} J$ Respir Crit Care Med 1998, I 58:597-60I.

20. Elliot JG, Jensen CM, Mutavdzic S, Lamb JP, Carroll NG, James AL: Aggregations of lymphoid cells in the airways of nonsmokers, smokers, and subjects with asthma. Am J Respir Crit Care Med 2004, 169(6):712-718.

21. Luhrmann A, Tschernig T, Pabst R: Stimulation of bronchus-associated lymphoid tissue in rats by repeated inhalation of aerosolized lipopeptide MALP-2. Pathobiology 2002, 70:266-269.

22. Lugton I: Mucosa-associated lymphoid tissues as sites for uptake, carriage and excretion of tubercle bacilli and other pathogenic mycobacteria. Immunol Cell Biol I999, 77:364-372.
23. Toyoshima M, Chida K, Sato A: Antigen uptake and subsequent cell kinetics in bronchus-associated lymphoid tissue. Respirology 2000, 5: | $4|-| 45$.

24. Morin MJ, Warner A, Fields BN: A pathway for entry of retroviruses into the host through $M$ cells of the respiratory tract. J Exp Med 1994, I 80:1523-1527.

25. Teitelbaum R, Schubert W, Gunther L, Kress Y, Macaluso F, Pollard JW, McMurray DN, Bloom BR: The $M$ cell as a portal of entry to the lung for the bacterial pathogen Mycobacterium tuberculosis. Immunity 1999, 10:641-650.

26. Gebert A, Steinmetz I, Fassbender S, Wendlandt $\mathrm{KH}$ : Antigen transport into Peyer's patches: increased uptake by constant numbers of M cells. Am J Pathol 2004, I 64:65-72.

27. Picker LJ, Butcher EC: Physiological and molecular mechanisms of lymphocyte homing. Annu Rev Immunol 1992, I0:56 I-59 I.

28. Cesta MF: Normal structure, function, and histology of mucosa-associated lymphoid tissue. Toxicol Pathol 2006, 34:599-608

29. Stewart S, Fishbein MC, Snell GI, Berry GJ, Boehler A, Burke MM, Glanville A, Gould FK, Magro C, Marboe CC, et al.: Revision of the 1996 working formulation for the standardization of nomenclature in the diagnosis of lung rejection. J Heart Lung Transplant 2007, 26: 1229-1242

30. Briskin M, Winsor-Hines D, Shyjan A, Cochran N, Bloom S, Wilson J, McEvoy LM, Butcher EC, Kassam N, Mackay CR, et al.: Human mucosal addressin cell adhesion molecule-I is preferentially expressed in intestinal tract and associated lymphoid tissue. Am J Pathol 1997, I 5 I:97- I I0.

31. Perry ME, Kirkpatrick WN, Happerfield LC, Gleeson MJ: Expression of adhesion molecules on the microvasculature of the pharyngeal tonsil (adenoid). Acta Otolaryngol Suppl I996, 523:47-5I.

32. Cyster JG: Chemokines and cell migration in secondary lymphoid organs. Science 1999, 286(5447):2098-2102.

33. Tanaka H, Saito S, Sasaki H, Arai H, Oki T, Shioya N: Morphological aspects of LFA-I/ICAM-I and VLA4/VCAM-I adhesion pathways in human lymph nodes. Pathol Int 1994, 44:268-279.

34. Michie SA, Streeter PR, Bolt PA, Butcher EC, Picker LJ: The human peripheral lymph node vascular addressin. An inducible endothelial antigen involved in lymphocyte homing. $A m J$ Pathol 1993, I43:1688-1698.

35. Ainslie MP, McNulty CA, Huynh T, Symon FA, Wardlaw AJ: Characterisation of adhesion receptors mediating lymphocyte adhesion to bronchial endothelium provides evidence for a distinct lung homing pathway. Thorax 2002, 57: 1054- 059.

36. Berg EL, Robinson MK, Warnock RA, Butcher EC: The human peripheral lymph node vascular addressin is a ligand for LECAM-I, the peripheral lymph node homing receptor. J Cell Biol 1991, I | 4:343-349.

37. van Dinther-Janssen AC, van Maarsseveen TC, Eckert H, Newman W, Meijer C): Identical expression of ELAM-I, VCAM-I, and ICAM-I in sarcoidosis and usual interstitial pneumonitis. J Pathol 1993, I 70:157-164.

38. Ohkawara Y, Yamauchi K, Maruyama N, Hoshi H, Ohno I, Honma M, Tanno $Y$, Tamura G, Shirato K, Ohtani H: In situ expression of the cell adhesion molecules in bronchial tissues from asthmatics with air flow limitation: in vivo evidence of VCAM-I/VLA-4 interaction in selective eosinophil infiltration. Am J Respir Cell Mol Biol 1995, 12:4-12.

39. Brodie SJ, de la Rosa C, Howe JG, Crouch J, Travis WD, Diem K: Pediatric AIDS-associated lymphocytic interstitial pneumonia and pulmonary arterio-occlusive disease: role of VCAMI/VLA-4 adhesion pathway and human herpesviruses. $\mathrm{Am} J$ Pathol 1999, I 54:1453-1464.

40. Sato A: Bronchus-associated lymphoid tissue (BALT). Nihon Kokyuki Gakkai Zasshi 2003:235-236.

4I. Pabst R, Gehrke I: Is the bronchus-associated lymphoid tissue (BALT) an integral structure of the lung in normal mammals, including humans? Am J Respir Cell Mol Biol I 990, 3: I 31 - I 35.

42. Dahl ME, Dabbagh K, Liggitt D, Kim S, Lewis DB: Viral-induced T helper type I responses enhance allergic disease by effects on lung dendritic cells. Nat Immunol 2004, 5:337-343.

43. Moyron-Quiroz JE, Rangel-Moreno J, Kusser K, Hartson L, Sprague F, Goodrich S, Woodland DL, Lund FE, Randall TD: Role of inducible bronchus associated lymphoid tissue (iBALT) in respiratory immunity. Nat Med 2004, 1 0:927-934. 
44. Iwata M, Sato A: Morphological and immunohistochemical studies of the lungs and bronchus-associated lymphoid tissue in a rat model of chronic pulmonary infection with Pseudomonas aeruginosa. Infect Immun I99I, 59:15|4-I520.

45. Pabst R, Durak D, Roos A, Luhrmann A, Tschernig T: TLR2/6 stimulation of the rat lung: effects on lymphocyte subsets, natural killer cells and dendritic cells in different parts of the airconducting compartments and at different ages. Immunology 2009, 126:132-139.

46. Sato $\mathrm{A}$, Chida $\mathrm{K}$, Iwata M, Hayakawa $\mathrm{H}$ : Study of bronchus-associated lymphoid tissue in patients with diffuse panbronchiolitis. Am Rev Respir Dis 1992, 146:473-478.

47. Sato A, Hayakawa H, Uchiyama H, Chida K: Cellular distribution of bronchus-associated lymphoid tissue in rheumatoid arthritis. Am J Respir Crit Care Med 1996, I 54:1903-1907.

48. Suda T, Chida K, Hayakawa H, Imokawa S, Iwata M, Nakamura H, Sato A: Development of bronchus-associated lymphoid tissue in chronic hypersensitivity pneumonitis. Chest 1999, I I 5:357-363.

49. Rangel-Moreno J, Hartson L, Navarro C, Gaxiola M, Selman M, Randall TD: Inducible bronchus-associated lymphoid tissue (iBALT) in patients with pulmonary complications of rheumatoid arthritis. / Clin Invest 2006, I | 6:3|83-3194.

50. Leslie KO, Trahan S, Gruden J: Pulmonary pathology of the rheumatic diseases. Semin Respir Crit Care Med 2007, 28:369-378.

5I. Chvatchko Y, Kosco-Vilbois MH, Herren S, Lefort J, Bonnefoy JY: Germinal center formation and local immunoglobulin $E$ (IgE) production in the lung after an airway antigenic challenge. J Exp Med 1996, 184:2353-2360.

52. Mikulowska-Mennis A, Xu B, Berberian JM, Michie SA: Lymphocyte migration to inflamed lacrimal glands is mediated by vascular cell adhesion molecule-I/alpha(4)beta(I) integrin, peripheral node addressin/l-selectin, and lymphocyte function-associated antigen-I adhesion pathways. Am J Pathol 200I, 159:67|-68I.

53. Campbell JJ, Brightling CE, Symon FA, Qin S, Murphy KE, Hodge M, Andrew DP, Wu L, Butcher EC, Wardlaw AJ): Expression of chemokine receptors by lung $T$ cells from normal and asthmatic subjects. J Immunol 200I, I 66:2842-2848.

Publish with Bio Med Central and every scientist can read your work free of charge

"BioMed Central will be the most significant development for disseminating the results of biomedical research in our lifetime. "

Sir Paul Nurse, Cancer Research UK

Your research papers will be:

- available free of charge to the entire biomedical community

- peer reviewed and published immediately upon acceptance

- cited in PubMed and archived on PubMed Central

- yours - you keep the copyright

Submit your manuscript here:

http://www.biomedcentral.com/info/publishing_adv.asp
BioMedcentral 